\title{
Childhood Adversity Increases Risk for Nicotine Dependence and Interacts with $\alpha 5$ Nicotinic Acetylcholine Receptor Genotype Specifically in Males
}

\author{
Pingxing Xie ${ }^{1,2}$, Henry R Kranzler ${ }^{3}$, Huiping Zhang ${ }^{2,4}$, David Oslin ${ }^{3}$, Raymond F Anton ${ }^{5}$, Lindsay A Farrer ${ }^{6}$ \\ and Joel Gelernter*, ${ }^{*}, 2,4$ \\ 'Department of Genetics, Yale University School of Medicine, New Haven, CT, USA; ${ }^{2}$ VA CT Healthcare Center, West Haven, CT, USA; \\ ${ }^{3}$ Department of Psychiatry, University of Pennsylvania, Philadelphia VA Medical Center, Philadelphia, PA, USA; ${ }^{4}$ Department of Psychiatry, \\ Yale University School of Medicine, New Haven, CT, USA; ${ }^{5}$ Department of Psychiatry, Center for Alcohol and Drug Programs, Medical University \\ of South Carolina, Charleston, SC, USA; ${ }^{6}$ Departments of Medicine, Neurology, Ophthalmology, Genetics and Genomics, Epidemiology, \\ and Biostatistics, Boston University Schools of Medicine and Public Health, Boston, MA, USA
}

\begin{abstract}
The relative importance of specific genetic and environmental factors in regulating nicotine dependence (ND) risk, including the effects on specific forms of childhood adversity on smoking risk, have been understudied. Genome-wide association studies and rodent models have demonstrated that the $\alpha 5$ nicotinic acetylcholine receptor gene (CHRNA5) is important in regulating nicotine intake. Childhood adversity increases the methylation level of the CHRNA5 promoter region in European Americans (EAs), an effect that was observed only in males (Zhang et al, submitted for publication). In view of this potential sex difference in the effects of early life experience on smoking, we investigated the presence of a sex-specific gene-by-environment effect of this marker on ND risk. A nonsynonymous SNP in CHRNA5 previously associated to ND and several related traits, rs 16969968, was genotyped in 2206 EAs (I30I men and 905 women). The main and interactive effects of childhood adversity and rs 16969968 genotype on diagnosis of ND and ND defined by dichotomized Fagerstrom test for ND (FTND) scores were explored. Men and women were analyzed separately to test for sex differences. Childhood adversity significantly increased ND risk in both sexes, and the effect in women was twice than that in men. Significant interactive effects of childhood adversity and rs 16969968 genotype were observed in men (ND: $O R=1.80,95 \% \mathrm{Cl}=1.18-2.73, P=0.0044 ; \mathrm{FTND}$ : $\mathrm{OR}=1.79,95 \% \mathrm{Cl}=1.1 \mathrm{I}-2.88, P=0.012)$. No interaction was found in women. This study provides evidence of a sex-specific gene $\times$ environment effect of CHRNA5 and childhood adversity on the risk for ND.

Neuropsychopharmacology (2012) 37, 669-676; doi:10.1038/npp.20II.240; published online 19 October 201 I
\end{abstract}

Keywords: CHRNA5; childhood adversity; gene-environment interaction; nicotine dependence; Fagerstrom test for nicotine dependence score

\section{INTRODUCTION}

In $2009,20.6 \%$ of the US population were current smokers (Blumberg and Luke, 2010). Smoking is a major risk factor for cancer, cardiovascular disease, stroke, and many other diseases. Smoking risk is known to be influenced by genetic factors. Twin studies identified moderate genetic influences on lifetime smoking behaviors (Carmelli et al, 1992; True et al, 1999). Several large genome-wide association studies

\footnotetext{
*Correspondence: Professor J Gelernter, Division of Human Genetics in Psychiatry, Department of Psychiatry, Yale University School of Medicine, VA CT Healthcare Center II6A2, 950 Campbell Avenue, West Haven, CT 065 I6, USA, Tel: + I 203932 57।I, Fax: + I 203 937 474I, E-mail: joel.gelernter@yale.edu

Received 26 July 201 I; revised 27 August 201 I; accepted 2 September 2011
}

identified significant association of polymorphisms in a cluster of three nicotinic acetylcholine receptor (nAChR) subunit genes, CHRNA5, CHRNA3, and CHRNB4 on chromosome 15q25.1 with smoking behaviors (Furberg et al, 2010; Liu et al, 2010; Thorgeirsson et al, 2010). Experiments in a rodent model demonstrated that nicotine activates $\alpha 5^{*}$ nAChRs through the medial habenulo-interpeduncular pathway, triggering an inhibitory signal to limit nicotine intake (Fowler et al, 2011). Therefore, mice with a null mutation in CHRNA5, which encodes the $\alpha 5 \mathrm{nAChR}$ subunit, exhibited markedly increased nicotine intake compared with wild-type mice. The most widely studied SNP in CHRNA5, rs16969968, corresponds to an aminoacid change in a highly conserved region (p.D398N). In vitro studies indicated that the risk allele (' $A$ ') reduced the response to a nicotine agonist (Bierut et al, 2008). 
In American populations, the minor allele frequency (MAF) of rs16969968 varies from about 6\% in African Americans (AAs) to about $35 \%$ in European Americans (EAs) (Bierut et al, 2008; Erlich et al, 2010; Johnson et al, 2010).

Childhood adversity increases the risk for many adult psychiatric disorders, including anxiety (Copeland et al, 2007), mood disorders (Widom et al, 2007), disruptive behavior (Rucklidge et al, 2006), and substance use disorders (Douglas et al, 2010; Kendler et al, 2000). However, its association with smoking is not well established. Among a few studies investigating the association between early environmental factors and smoking, a large study found a strong association between childhood abuse and early initiation of smoking in women (Jun et al, 2008). In that study, young women who experienced both childhood physical and sexual abuse were twice as likely to start smoking by age 14 as those who did not experience abuse. In a second study, women with both childhood physical and sexual abuse had a 3.5-fold greater likelihood of smoking initiation than those without childhood abuse (Nichols and Harlow, 2004). A third study showed a strong and cumulative association between childhood adversity and 'ever smoking,' 'current smoking,' or 'heavy smoking' (Anda et al, 1999). To our knowledge, no studies have assessed the effects of childhood adverse experiences on a $D S M-I V$ diagnosis of nicotine dependence (ND) or Fagerstrom test for ND (FTND) score (Fagerstrom, 1978; Heatherton et al, 1991).

One possible reason for the increased risk of smoking in people who have experienced childhood adversity is that nicotine can alleviate negative mood states (Carmody, 1989). In an animal study, environmental factors, especially stress, enhanced $\mathrm{nAChR}$ responses in rats, an effect that could theoretically increase nicotine abuse vulnerability (Fagen et al, 2007).

Long-term consequences of early life experiences may also be affected through epigenetic mechanisms. For example, maternal behaviors of rats altered their offspring's DNA methylation level at the glucocorticoid receptor gene promoter region (Weaver et al, 2004). In humans, childhood abuse was also seen to influence glucocorticoid receptor gene expression through epigenetic programming in suicide victims (McGowan et al, 2009). Altered expression of genes in the hypothalamic-pituitary-adrenal (HPA) axis affects the HPA stress response, and thus may increase the risk to develop psychiatric disorders later in life.

Despite evidence that both genetic and environmental factors contribute to smoking behavior, to our knowledge, there is only one published study (Myers et al, 2010) investigating the interactive effect of early life stress and rs16969968 genotype on smoking-related behaviors. In that small study $(n=135)$, the phenotype was smoking motives and no interactive effect was found.

Recently, we observed in a sample of EAs, that childhood adversity was associated with greater methylation of one CpG site at the CHRNA5 promoter region (DiffScore $=27.7$, $P=0.002$ ) by Illumina GoldenGate Methylation Array analysis of peripheral blood DNA (Zhang et al, submitted for publication). This methylation change was observed only in males. Greater methylation potentially decreases CHRNA5 expression. Because CHRNA5 has been shown in both rodent models and human subjects to be functionally important in smoking, we hypothesized that an altered methylation level in the CHRNA5 promoter might be involved in regulating smoking behaviors. Further, the methylation data are consistent with an animal model where decreased expression (as would be expected from increased methylation subsequent to childhood abuse) would increase nicotine intake (Fowler et al, 2011). These observations also led us to explore the sex-specific susceptibility of ND, especially under the influence of early life stress. Since the minor allele of the nonsynonymous SNP rs16969968 reduced the response to a nicotine agonist (Bierut et al, 2008), we designed this study to assess the interactive effect of childhood adversity and rs16969968 genotypes on the diagnosis of ND and ND defined by dichotomized FTND scores. Considering the greater methylation level of CHRNA5 associated with childhood adversity, EA men and women were analyzed separately to test for a hypothesized sex effect.

\section{SUBJECTS AND METHODS}

\section{Subjects}

Because the MAF of rs16969968 in AAs is only about 6\%, and thus too small for a $\mathrm{G} \times \mathrm{E}$ study, only EAs $(n=2206)$ were included in this study. The subjects were recruited for linkage and association studies of the genetics of drug and alcohol dependence at five US sites: the University of Connecticut Health Center $(n=1102)$, Yale University School of Medicine $(n=866)$, the Medical University of South Carolina $(n=155)$, McLean Hospital of Harvard Medical School $(n=57)$, and the University of Pennsylvania School of Medicine $(n=26)$. Of this total, 435 subjects were recruited as family members; each family included at minimum one affected sibling pair for substance dependence (Gelernter et al, 2005, 2006). The remaining 1771 subjects were recruited as substance dependence cases and unaffected controls. After receiving a complete description of the study, subjects gave written informed consent to participate. The institutional review board at each of the participating sites approved the study protocol and consent procedures.

\section{Smoking Phenotypes and Childhood Adversity Index}

All subjects were interviewed using an electronic version of the Semi-Structured Assessment for Drug Dependence and Alcoholism (SSADDA) to derive diagnoses for lifetime substance dependence according to DSM-IV criteria (Pierucci-Lagha et al, 2007, 2005). Participants were asked whether they had ever tried any form of tobacco, and we included subjects who answered 'yes' to the question in this study. That is, they were all tobacco exposed. By selecting controls that had tried smoking, the study focused on the development of ND instead of smoking initiation. The reliability of the SSADDA for a lifetime DSM- $I V$ diagnosis of ND was excellent, with an inter-rater and test-retest reliability $[\kappa]$ of 0.77 and 0.97 , respectively (Pierucci-Lagha et al, 2005). The ND section of the SSADDA also has the FTND (Fagerstrom, 1978; Heatherton et al, 1991) embedded in it.

Childhood adversity was assessed by the SSADDA Environment section. Participants were asked whether 
either of their parents died before they were 6 years old and whether before the age of 13 they had witnessed or experienced a violent crime, had been sexually abused, or had been physically abused. Endorsement of any of these adverse childhood experiences was coded as exposure to childhood adversity.

\section{Genotyping}

Blood or saliva samples were collected from all the participants for genetic analysis. DNA was extracted from immortalized cell lines or directly from blood or saliva. The TaqMan method (Shi, 2001) was used to genotype SNP rs16969968 at the Yale University School of Medicine. Genotypes were assayed in duplicate to increase accuracy and call rate. Discordant calls were discarded. The final call rate was $98.3 \%$. Forty-one ancestry informative markers were genotyped to analyze the population group of each subject. These 41 markers included 36 short tandem repeats markers and 5 SNPs that were selected for this purpose. Detailed ancestry informative marker information and genotyping methods have been reported previously (Xie et al, 2009; Yang et al, 2005).

\section{Statistical Analysis}

The population group of each participant was ascertained by STRUCTURE analysis (Falush et al, 2003; Pritchard and Rosenberg, 1999; Pritchard et al, 2000) of ancestry informative markers. We used admixture and allele frequency-correlated models. The program was set at 500000 burn-in iterations followed by 500000 repeats. All of the subjects in this study had an African ancestry proportion score $<0.500$, and were thus classified as EA.

Because FTND scores (range 0-10) are not normally distributed in this sample, we dichotomized FTND scores such that subjects with FTND scores $\geqslant 4$ were classified as nicotine-dependent cases and those with FTND scores $\leqslant 1$ were classified as controls. Logistic regression was used to explore the main effects of rs16969968 genotype and childhood adversity on ND or dichotomized FTND. The regression model for the analysis of the entire sample included variables for rs16969968 genotype (additively coded as 0,1 , or 2 copies of the minor allele), childhood adversity (coded as 0 or 1), a continuous ancestry proportion score, sex, and age. Generalized estimating equations (Zeger and Liang, 1986) were applied to fit the logistic regression model to account for the correlated data from individuals in the same family. This analysis was also performed in subgroups of males and females. To test for interaction of rs 16969968 genotype and childhood adversity on ND risk or dichotomized FTND, an interaction term was introduced in the logistic regression models. Based on our hypothesis, EA males and females were predicted to show different $\mathrm{G} \times \mathrm{E}$ effects, and were therefore analyzed separately.

Since most of the subjects with lifetime ND were also co-morbid for alcohol, cocaine and/or opioid dependence, additional models including terms for these co-morbidities and their interactions with rs16969968 genotype and childhood adversity were examined. All regression analyses were performed using SAS 9.2 (SAS, Cary, NC).

\section{RESULTS}

\section{Main Effects of Childhood Adversities and CHRNA5 Rs16969968 Genotype on ND}

A total of 2206 EA subjects were included in this study, including 1301 men and 905 women. The race of the participants was confirmed by analyzing the ancestry informative markers. Although all subjects had been exposed to nicotine, 1461 of them $(66.2 \%)$ were diagnosed as having lifetime ND based on DSM-IV criteria. Among men, the mean age was 38.1 (SD 11.0), 68.1\% received a diagnosis of lifetime ND, and the mean FTND score in those with a diagnosis of ND was 5.66 (SD 1.95). Among women, the mean age was 37.2 years (SD 11.0), $63.5 \%$ had a lifetime diagnosis of ND, and the mean FTND score in those with a diagnosis of ND was 5.75 (SD 1.95).

We assessed four categories of childhood adversity: namely parental death before age 6 , witnessing or being a victim of a violent crime before age 13, experiencing sexual abuse before age 13, and experiencing physical abuse before age 13 . More than one-third of men (37.3\%) and nearly half of women $(48.5 \%)$ reported one or more adverse childhood experiences. The distribution of the four categories of childhood adversity by sex is shown in Table 1 . In this group of subjects, more women than men had been sexually or physically abused. Table 2 presents the main effects of childhood adversity on the diagnosis of ND and on ND defined by dichotomized FTND. Childhood adversity was significantly associated with risk for $\mathrm{ND}$ in both men (ND: $\mathrm{OR}=1.94,95 \% \mathrm{CI}=1.50-2.52, \quad P<0.0001$; FTND: $\mathrm{OR}=1.71,95 \% \mathrm{CI}=1.29-2.29, \quad P=0.0002)$ and women $(\mathrm{ND}: \mathrm{OR}=3.56,95 \% \mathrm{CI}=2.64-4.79, \quad P<0.0001$; FTND: $\mathrm{OR}=3.76,95 \% \mathrm{CI}=2.75-5.15, P<0.0001)$. There was a greater risk of ND due to childhood adverse experiences in women than men $(P<0.0001)$.

We examined the effects of the different categories of childhood adversity on the diagnosis of ND and on ND defined by dichotomized FTND. After adjusting for age, ancestry proportion score, and genotype, witnessing or being a victim of a violent crime or physical abuse were significantly associated with increased risk for a diagnosis of ND in men; among women, in addition to witnessing or being a victim of a violent crime or physical abuse, sexual abuse was also significantly associated with a diagnosis of ND (Table 1). In both sexes, a greater number of adverse childhood experiences increased ND risk (Figure 1). Among individuals without childhood adversity, women had a lower rate of ND than men; while among those who experienced the same number of categories of adverse childhood experiences, there was no sex difference on the risk of developing ND (Figure 1). Similar association patterns were observed for ND defined by dichotomized FTND scores (Table 1).

The genotype distribution of rs 16969968 was $11.9 \%$ AA, $41.9 \% \mathrm{AG}$, and $46.2 \% \mathrm{GG}$, consistent with previous studies and with Hardy-Weinberg equation equilibrium expectations (Bierut et al, 2008; Erlich et al, 2010; Johnson et al, 2010). After adjusting for age, sex, ancestry proportion score, and childhood adversity, rs16969968 genotype was not significantly associated with ND (ND: OR $=1.13,95 \%$ $\mathrm{CI}=0.98-1.29, P=0.087$; FTND: $\mathrm{OR}=1.12,95 \% \mathrm{CI}=0.97-$ $1.30, P=0.12$; Table 2). This is consistent with results we 
Table I Distribution of the Four Categories of Childhood Adversity and Their Effects on a Diagnosis of Nicotine Dependence and Nicotine Dependence Defined by Dichotomized FTND Scores

\begin{tabular}{|c|c|c|c|c|c|c|}
\hline & \multicolumn{3}{|c|}{ Men } & \multicolumn{3}{|c|}{ Women } \\
\hline & \multicolumn{6}{|c|}{ DSM-IV nicotine dependence } \\
\hline Parental death & 3.5 & $1.54(0.74-3.19)$ & 0.22 & 3.5 & $0.82(0.36-1.85)$ & 0.64 \\
\hline Sexual abuse & 12.5 & $1.35(0.88-2.07)$ & 0.17 & 29.1 & $2.52(1.74-3.66)$ & $<0.0001$ \\
\hline Physical abuse & 15.4 & $1.90(1.29-2.79)$ & 0.0005 & 21.5 & $2.52(1.64-3.87)$ & $<0.0001$ \\
\hline
\end{tabular}

Fagerstrom test for nicotine dependence

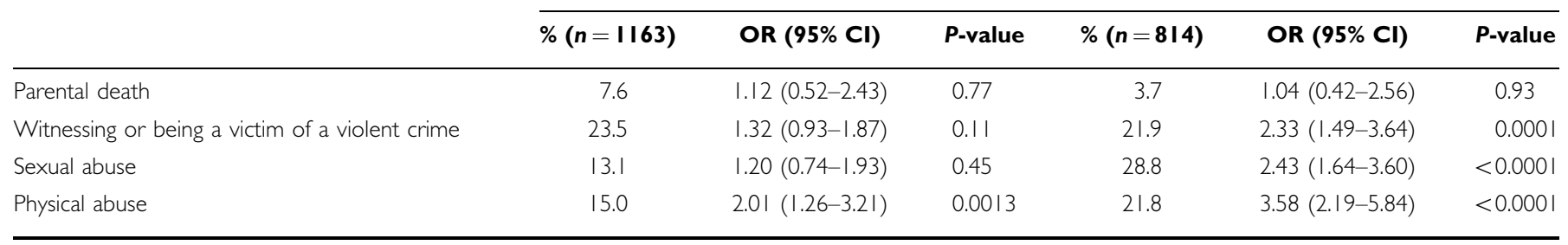

Table 2 Main Effects of Childhood Adversity and rs 6969968 Genotype on a Diagnosis of Nicotine Dependence and Nicotine Dependence Defined by Dichotomized FTND Scores

\begin{tabular}{|c|c|c|c|c|c|c|}
\hline & \multicolumn{2}{|c|}{ Whole sample } & \multicolumn{2}{|c|}{ Men } & \multicolumn{2}{|c|}{ Women } \\
\hline & OR $(95 \% \mathrm{Cl})$ & $P$-value & OR $(95 \% \mathrm{Cl})$ & $P$-value & OR $(95 \% \mathrm{Cl})$ & $P$-value \\
\hline \multicolumn{7}{|c|}{ DSM-IV nicotine dependence } \\
\hline CA & $2.56(2.10-3.13)$ & $<0.0001$ & $1.94(1.50-2.52)$ & $<0.0001$ & $3.56(2.64-4.79)$ & $<0.0001$ \\
\hline rs 6969968 & $1.13(0.98-1.29)$ & 0.087 & $1.11(0.93-1.34)$ & 0.22 & $1.12(0.91-1.39)$ & 0.29 \\
\hline Age & $0.99(0.98-1.00)$ & 0.055 & $0.99(0.98-1.00)$ & 0.041 & $0.99(0.98-1.01)$ & 0.43 \\
\hline \multicolumn{7}{|l|}{ Sex } \\
\hline Female & 1.0 & & & & & \\
\hline Male & $1.35(1.12-1.63)$ & 0.0016 & & & & \\
\hline \multicolumn{7}{|c|}{ Fagerstrom test for nicotine dependence } \\
\hline$C A$ & $2.51(2.01-3.12)$ & $<0.000$ । & $1.71(1.29-2.29)$ & 0.0002 & $3.76(2.75-5.15)$ & $<0.0001$ \\
\hline rs 16969968 & $1.12(0.97-1.30)$ & 0.12 & $1.17(0.96-1.44)$ & 0.12 & $1.06(0.86-1.32)$ & 0.58 \\
\hline Age & $1.00(0.99-1.01)$ & 0.39 & $0.99(0.98-1.01)$ & 0.37 & $1.00(0.98-1.01)$ & 0.58 \\
\hline \multicolumn{7}{|l|}{ Sex } \\
\hline Female & 1.0 & & & & & \\
\hline Male & $1.60(1.30-1.97)$ & $<0.0001$ & & & & \\
\hline
\end{tabular}

Abbreviation: CA, childhood adversity.

reported earlier in an overlapping sample (Sherva et al, 2010).

\section{Interactive Effect of Childhood Adversity and Rs16969968 Genotype on Smoking}

After adjusting for all of the main effects (ie, age, ancestry proportion score, genotype, and childhood adversity), logistic regression analysis showed that in men, the interaction of childhood adversity with rs16969968 genotype was significantly associated with risk for a diagnosis of ND $(\mathrm{OR}=1.80,95 \% \mathrm{CI}=1.18-2.73, P=0.0044$; Table 3 ; Figure 2a). Although in men with no adverse childhood experiences, those homozygous for the A allele of rs16969968 were less likely to develop ND than those with the GA or GG genotype, the difference was not significant 


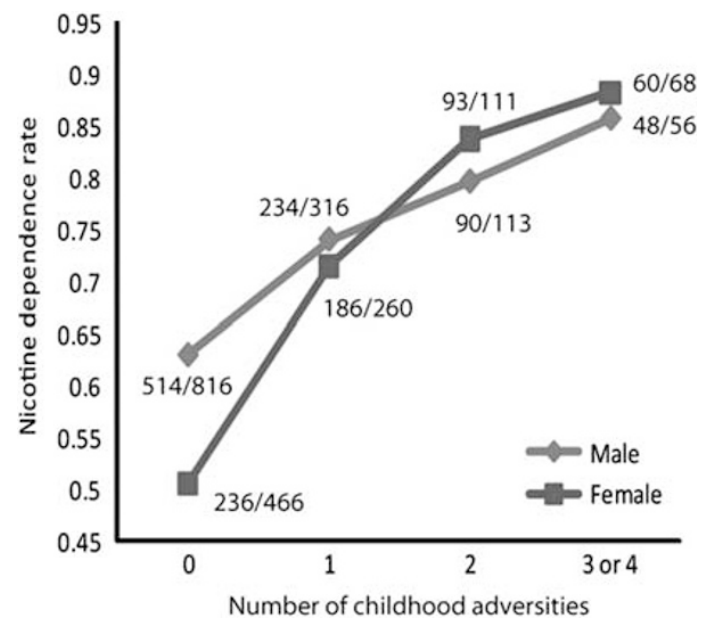

Figure I Cumulative association of numbers of categories of childhood adversity experienced and rate of nicotine dependence diagnosis in men and women. The number of subjects with nicotine dependence and the total number of participants in each group are shown for each level of childhood adversity.

Table 3 Interactive Effects of Childhood Adversity (With All Four Categories of Childhood Adversity Combined) and rsI 6969968 Genotype on the Likelihood of a Diagnosis of Nicotine Dependence and Nicotine Dependence Defined by Dichotomized FTND Scores

\begin{tabular}{|c|c|c|c|c|}
\hline & \multicolumn{2}{|l|}{ Men } & \multicolumn{2}{|c|}{ Women } \\
\hline & OR (95\% Cl) & $P$-value & OR $(95 \% \mathrm{Cl})$ & $P$-value \\
\hline \multicolumn{5}{|c|}{ DSM-IV nicotine dependence } \\
\hline CA & $1.38(0.98-1.96)$ & 0.066 & $3.84(2.55-5.76)$ & $<0.000$ I \\
\hline rs 16969968 & $0.95(0.77-1.17)$ & 0.63 & $1.17(0.90-1.53)$ & 0.24 \\
\hline$C A \times r s 16969968$ & $1.80(1.18-2.73)$ & 0.0044 & $0.89(0.58-1.37)$ & 0.61 \\
\hline Age & $0.99(0.98-1.00)$ & 0.038 & $0.99(0.98-1.01)$ & 0.43 \\
\hline \multicolumn{5}{|c|}{ Fagerstrom test for nicotine dependence } \\
\hline CA & $1.24(0.84-1.82)$ & 0.28 & $3.29(2.16-5.02)$ & $<0.000$ I \\
\hline rs 16969968 & $1.00(0.79-1.28)$ & 0.98 & $0.99(0.75-1.30)$ & 0.94 \\
\hline$C A \times r s 16969968$ & $1.79(1.11-2.88)$ & 0.012 & $1.23(0.78-1.94)$ & 0.38 \\
\hline Age & $0.99(0.98-1.01)$ & 0.36 & $1.00(0.98-1.01)$ & 0.56 \\
\hline
\end{tabular}

Abbreviation: CA, childhood adversity.

$\left(\chi^{2}=2.22, \mathrm{df}=2, P=0.33\right)$. However, among men who experienced childhood adversity, there was a significant effect of genotype $\left(\chi^{2}=7.85, \mathrm{df}=2, P=0.020\right)$, with the AA genotype group having the highest risk to develop ND. Interestingly, no interactive effect was observed in the women $(\mathrm{OR}=0.89,95 \% \mathrm{CI}=0.58-1.37, P=0.61$; Table 3; Figure $2 \mathrm{~b}$ ). We tested $\mathrm{G} \times \mathrm{E}$ effects by considering only those categories of childhood adversity that were significantly associated with a diagnosis of ND: namely, witnessing or being a victim of a violent crime or physical abuse in men and witnessing or being a victim of a violent crime, physical abuse, or sexual abuse in women. The results were very similar to those obtained when all four categories
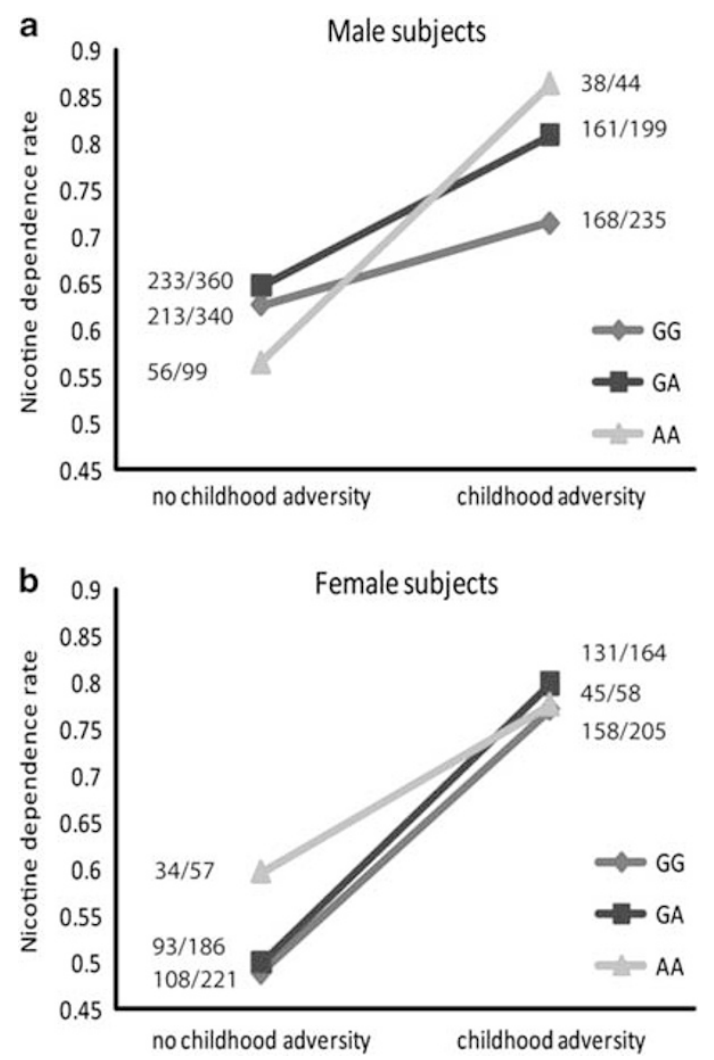

Figure 2 rs 6969968 genotype interacted with childhood adversity to modify risk for the diagnosis of nicotine dependence in EA men (a), but not in EA women (b). The number of subjects with nicotine dependence and the total number of participants in each group are shown. Men homozygous for the A allele had the highest risk of nicotine dependence when exposed to childhood adversity.

of childhood adversity were considered (Supplementary Table 1).

The same logistic regression analyses were performed using the dichotomized FTND score as the dependent variable. ND and dichotomized FTND were highly correlated, and their logistic regression results were accordingly very similar: namely, a $\mathrm{G} \times \mathrm{E}$ effect was observed only in men (men: $\mathrm{OR}=1.79, \quad 95 \% \quad \mathrm{CI}=1.11-2.88, \quad P=0.012$; women: $\mathrm{OR}=1.23,95 \% \mathrm{CI}=0.78-1.94, P=0.38$; Table 3; Supplementary Table 1).

In this sample, $98.0 \%$ of the men and $97.7 \%$ of the women had lifetime diagnoses of alcohol, cocaine and/or opioid dependence. To explore the effects of the co-morbid disorders, we added the main effects of these diagnoses, and their interactions with rs16969968 genotype and childhood adversity to the original $\mathrm{G} \times \mathrm{E}$ model (ie, including all four categories of childhood adversity). For both men and women, alcohol, cocaine and opioid dependence were significantly associated with ND, but none of the six interaction terms that included these factors was significant, and thus were removed from the models. When adjusted for alcohol, cocaine and opioid dependence, the results of the interaction of childhood adversity with rs16969968 genotype were very similar to those from the original models: namely, the interaction was observed in men (ND: $\mathrm{OR}=1.86,95 \% \mathrm{CI}=1.19-2.92, P=0.0060$; FTND: $\mathrm{OR}=2.01,95 \% \mathrm{CI}=1.21-3.33, P=0.0058)$, but not women 
(ND: $\quad \mathrm{OR}=0.97, \quad 95 \% \quad \mathrm{CI}=0.58-1.62, \quad P=0.91 ; \quad$ FTND: $\mathrm{OR}=1.68,95 \% \mathrm{CI}=0.96-2.95, P=0.079$; Supplementary Table 2).

To exclude the possibility that the gene-environment correlation was a confounder in this study, the distribution of childhood adversity with rs16969968 genotype was examined by $\chi^{2}$ test in both men and women. No significant association was observed in either group.

\section{DISCUSSION}

In this study, we investigated the main and interactive effects of a nonsynonymous SNP at CHRNA5 (rs16969968) and childhood adversity on the risk for a lifetime diagnosis of ND and ND defined by dichotomized FTND scores in a sample of 2206 EA subjects (1301 men and 905 women). Childhood adversity was significantly associated with risk for ND. Based on our previous observation that childhood adversity increased the methylation level of the CHRNA5 promoter region only in EA men (Zhang et al, submitted for publication), and results from a functional study that the risk allele of rs16969968 decreased nAChR response to a nicotinic agonist (Bierut et al, 2008), we hypothesized that there would be a sex difference in the $\mathrm{G} \times \mathrm{E}$ effect. Consistent with this prediction, we observed a statistically reliable interaction only in men.

Previous studies examining the effect of early life stress on smoking have mainly focused on smoking initiation (Anda et al, 1999; Jun et al, 2008; Nichols and Harlow, 2004). We selected only subjects who had smoked, and demonstrated that childhood adversity increased the risk for chronic smoking leading to ND. We found that greater adversity increased ND risk (Figure 1). In addition, we found that the effect of early life stress on ND risk in females $(\mathrm{OR}=3.7)$ was nearly twice than that in males $(\mathrm{OR}=2.0)$. This may be partially attributable to the different types and severity levels of childhood trauma experienced by men and women. Among the four categories of childhood adversity assessed in this study, witnessing or being the victim of a violent crime or physical abuse were significantly associated with a diagnosis of ND in both men and women, while the effect of sexual abuse was significant only in women.

In agreement with our epigenetic methylation study (Zhang et al, submitted for publication), we observed a sex difference in the interaction of childhood adversity and rs16969968 genotype on ND risk. Men homozygous for the rs16969968 A allele who had experienced greater childhood adversity had a higher risk of ND than those with the AG or GG genotypes (Figure 2a). However, rs16969668 had little effect on the association of childhood adversity with ND risk in females (Figure 2b). Although most of the sample had co-occurring dependence on other substances, dependence on multiple substances did not alter the interaction of rs16969968 genotype and childhood adversity on risk of ND in either sex.

Studies in rodent models and human subjects have demonstrated that early life experience causes epigenetic changes in genes encoding nervous system proteins, especially those in the HPA axis (McGowan et al, 2009; Weaver et al, 2004), which could explain the long-term behavioral influences of childhood adversity. In addition, epigenetic changes are known to differ by sex. Increased promoter region methylation almost always decreases gene expression (Jaenisch and Bird, 2003). Based on our previous and current studies, we hypothesize that in males, after experiencing childhood adversity, the expression level of the $\alpha 5 \mathrm{nAChR}$ subunit decreases because of increased methylation in the CHRNA5 promoter region. Since the $\alpha 5 \mathrm{nAChR}$ subunit appears to trigger negative feedback and controls nicotine intake (Fowler et al, 2011), decreased CHRNA5 expression would be predicted to increase the risk for ND. In addition, the functional effect of the A allele of rs16969968 appears to be a reduced response to nicotinic agonists, rather than a difference in the expression level of CHRNA5 (Bierut et al, 2008). Consistent with this model, males who experienced childhood adversity (with concomitantly decreased $\alpha 5 \mathrm{nAChR}$ expression due to epigenetic effects), with the AA genotype of rs16969968 (which also decreases $\alpha 5 \mathrm{nAChR}$ function), would have the highest risk to develop ND. In females, however, the effect of childhood adversity does not depend upon methylation programming of CHRNA5 (Zhang et al, submitted for publication). Therefore, there is no interaction between childhood adversity and rs16969968 genotype. Further functional studies are needed to test this hypothesis.

Epigenetic changes are known to vary by sex, largely due to differential exposure to hormones during development (McCarthy et al, 2009; Nugent and McCarthy, 2011). The sex-specific methylation level change in the promoter region of CHRNA5 after childhood trauma may be caused by steroid hormone-dependent regulation. Childhood adversity causes methylation changes in the genes encoding the glucocorticoid receptor (McGowan et al, 2009; Weaver et $a l, 2004$ ) and the brain-derived neurotropic factor (Roth et al, 2009). Studies of these genes have not shown any sex differences in methylation changes. Evidence from both animal models and human studies has accumulated, showing that males and females may have different responses to early life experiences (Gross et al, 2010; Heim et al, 2009; Newman et al, 2009), and thus for future $\mathrm{G} \times \mathrm{E}$ studies, it will be important to consider sex differences.

\section{ACKNOWLEDGEMENTS}

We thank the individuals and families participating in this work and the interviewers at all the participating sites for collecting the data. This study was supported by NIH Grants R01 DA12690, R01 DA12849, and R01 AA11330.

\section{DISCLOSURE}

Dr Kranzler has received consulting fees from Alkermes, GlaxoSmithKline, Gilead, and Lundbeck and research support from Merck. Dr Anton reports for the last 2 years, being a consultant for Eli Lilly, GlaxoSmithKline, and Alkermes. Drs Kranzler and Anton also report associations with Eli Lilly, Merck, Janssen, Schering Plough, Lundbeck, Alkermes, GlaxoSmithKline, Abbott, and Johnson \& Johnson, as these companies provide support to the ACNP Alcohol Clinical Trials Initiative (ACTIVE) and they receive support from ACTIVE. Dr Gelernter reports that he has received compensation for professional services in the 
previous 3 years from the following entities: Yale University School of Medicine, Veterans Affairs Healthcare System (VA), and the National Institutes of Health (NIAAA, NIDA, and NIMH), and related to academic lectures and editorial functions in various scientific venues (including the ACNP). The other authors declared no conflict of interest.

\section{REFERENCES}

Anda RF, Croft JB, Felitti VJ, Nordenberg D, Giles WH, Williamson DF et al (1999). Adverse childhood experiences and smoking during adolescence and adulthood. JAMA 282: 1652-1658.

Bierut LJ, Stitzel JA, Wang JC, Hinrichs AL, Grucza RA, Xuei X et al (2008). Variants in nicotinic receptors and risk for nicotine dependence. Am J Psychiatry 165: 1163-1171.

Blumberg SJ, Luke JV (2010). Wireless Substitution: Early Release of Estimates from the National Health Interview Survey, JulyDecember 2009. CDC/National Center for Health Statistics, June 2011. Available from: http://www.cdc.gov/nchs/nhis.htm.

Carmelli D, Swan GE, Robinette D, Fabsitz R (1992). Genetic influence on smoking - a study of male twins. N Engl J Med 327: 829-833.

Carmody TP (1989). Affect regulation, nicotine addiction, and smoking cessation. J Psychoactive Drugs 21: 331-342.

Copeland WE, Keeler G, Angold A, Costello EJ (2007). Traumatic events and posttraumatic stress in childhood. Arch Gen Psychiatry 64: $577-584$.

Douglas KR, Chan G, Gelernter J, Arias AJ, Anton RF, Weiss RD et al (2010). Adverse childhood events as risk factors for substance dependence: partial mediation by mood and anxiety disorders. Addict Behav 35: 7-13.

Erlich PM, Hoffman SN, Rukstalis M, Han JJ, Chu X, Linda Kao WH et al (2010). Nicotinic acetylcholine receptor genes on chromosome 15q25.1 are associated with nicotine and opioid dependence severity. Hum Genet 128: 491-499.

Fagen ZM, Mitchum R, Vezina P, McGehee DS (2007). Enhanced nicotinic receptor function and drug abuse vulnerability. $J$ Neurosci 27: 8771-8778.

Fagerstrom KO (1978). Measuring degree of physical dependence to tobacco smoking with reference to individualization of treatment. Addict Behav 3: 235-241.

Falush D, Stephens M, Pritchard JK (2003). Inference of population structure using multilocus genotype data: linked loci and correlated allele frequencies. Genetics 164: 1567-1587.

Fowler CD, Lu Q, Johnson PM, Marks MJ, Kenny PJ (2011). Habenular alpha5 nicotinic receptor subunit signalling controls nicotine intake. Nature 471: 597-601.

Furberg H, Kim Y, Dackor J, Boerwinkle E, Franceschini N, Ardissino $\mathrm{D}$ et al (2010). Genome-wide meta-analyses identify multiple loci associated with smoking behavior. Nat Genet 42: 441-447.

Gelernter J, Panhuysen C, Weiss R, Brady K, Hesselbrock V, Rounsaville B et al (2005). Genomewide linkage scan for cocaine dependence and related traits: significant linkages for a cocainerelated trait and cocaine-induced paranoia. Am J Med Genet B Neuropsychiatr Genet 136B: 45-52.

Gelernter J, Panhuysen C, Wilcox M, Hesselbrock V, Rounsaville B, Poling $J$ et al (2006). Genomewide linkage scan for opioid dependence and related traits. Am J Hum Genet 78: 759-769.

Gross CM, Flubacher A, Tinnes S, Heyer A, Scheller M, Herpfer I et al (2010). Early life stress stimulates hippocampal reelin gene expression in a sex-specific manner: evidence for corticosteronemediated action. Hippocampus (e-pub ahead of print 6 December 2010).

Heatherton TF, Kozlowski LT, Frecker RC, Fagerstrom KO (1991). The Fagerstrom test for nicotine dependence: a revision of the Fagerstrom tolerance questionnaire. Br J Addict 86: 1119-1127.

Heim C, Bradley B, Mletzko TC, Deveau TC, Musselman DL, Nemeroff CB et al (2009). Effect of childhood trauma on adult depression and neuroendocrine function: sex-specific moderation by CRH receptor 1 gene. Front Behav Neurosci 3: 41.

Jaenisch R, Bird A (2003). Epigenetic regulation of gene expression: how the genome integrates intrinsic and environmental signals. Nat Genet 33(Suppl): 245-254.

Johnson EO, Chen LS, Breslau N, Hatsukami D, Robbins T, Saccone NL et al (2010). Peer smoking and the nicotinic receptor genes: an examination of genetic and environmental risks for nicotine dependence. Addiction (Abingdon, England) 105: 2014-2022.

Jun HJ, Rich-Edwards JW, Boynton-Jarrett R, Austin SB, Frazier AL, Wright RJ (2008). Child abuse and smoking among young women: the importance of severity, accumulation, and timing. $J$ Adolesc Health 43: 55-63.

Kendler KS, Bulik CM, Silberg J, Hettema JM, Myers J, Prescott CA (2000). Childhood sexual abuse and adult psychiatric and substance use disorders in women: an epidemiological and cotwin control analysis. Arch Gen Psychiatry 57: 953-959.

Liu JZ, Tozzi F, Waterworth DM, Pillai SG, Muglia P, Middleton L et al (2010). Meta-analysis and imputation refines the association of $15 \mathrm{q} 25$ with smoking quantity. Nat Genet 42: 436-440.

McCarthy MM, Auger AP, Bale TL, De Vries GJ, Dunn GA, Forger NG et al (2009). The epigenetics of sex differences in the brain. J Neurosci 29: 12815-12823.

McGowan PO, Sasaki A, D’Alessio AC, Dymov S, Labonte B, Szyf M et al (2009). Epigenetic regulation of the glucocorticoid receptor in human brain associates with childhood abuse. Nat Neurosci 12: $342-348$

Myers US, Hutchison KE, Filbey FM (2010). Large variability in smokers obscure the $\mathrm{G} \times \mathrm{E}$ effects on tobacco dependence. Psychiatry Res 177: 369-370.

Newman TK, Parker CC, Suomi SJ, Goldman D, Barr CS, Higley JD (2009). DRD1 5'UTR variation, sex and early infant stress influence ethanol consumption in rhesus macaques. Genes Brain Behav 8: 626-630.

Nichols HB, Harlow BL (2004). Childhood abuse and risk of smoking onset. J Epidemiol Community Health 58: 402-406.

Nugent BM, McCarthy MM (2011). Epigenetic underpinnings of developmental sex differences in the brain. Neuroendocrinology 93: $150-158$.

Pierucci-Lagha A, Gelernter J, Chan G, Arias A, Cubells JF, Farrer L et al (2007). Reliability of DSM-IV diagnostic criteria using the semi-structured assessment for drug dependence and alcoholism (SSADDA). Drug Alcohol Depend 91: 85-90.

Pierucci-Lagha A, Gelernter J, Feinn R, Cubells JF, Pearson D, Pollastri A et al (2005). Diagnostic reliability of the semistructured assessment for drug dependence and alcoholism (SSADDA). Drug Alcohol Depend 80: 303-312.

Pritchard JK, Rosenberg NA (1999). Use of unlinked genetic markers to detect population stratification in association studies. Am J Hum Genet 65: 220-228.

Pritchard JK, Stephens M, Donnelly P (2000). Inference of population structure using multilocus genotype data. Genetics 155: 945-959.

Roth TL, Lubin FD, Funk AJ, Sweatt JD (2009). Lasting epigenetic influence of early-life adversity on the BDNF gene. Biol Psychiatry 65: 760-769.

Rucklidge JJ, Brown DL, Crawford S, Kaplan BJ (2006). Retrospective reports of childhood trauma in adults with ADHD. J Atten Disord 9: 631-641.

Sherva R, Kranzler HR, Yu Y, Logue MW, Poling J, Arias AJ et al (2010). Variation in nicotinic acetylcholine receptor genes is associated with multiple substance dependence phenotypes. Neuropsychopharmacology 35: 1921-1931.

Shi MM (2001). Enabling large-scale pharmacogenetic studies by high-throughput mutation detection and genotyping technologies. Clin Chem 47: 164-172. 
Thorgeirsson TE, Gudbjartsson DF, Surakka I, Vink JM, Amin N, Geller F et al (2010). Sequence variants at CHRNB3-CHRNA6 and CYP2A6 affect smoking behavior. Nat Genet 42: 448-453.

True WR, Xian H, Scherrer JF, Madden PA, Bucholz KK, Heath AC et al (1999). Common genetic vulnerability for nicotine and alcohol dependence in men. Arch Gen Psychiatry 56: 655-661.

Weaver IC, Cervoni N, Champagne FA, D’Alessio AC, Sharma S, Seckl JR et al (2004). Epigenetic programming by maternal behavior. Nat Neurosci 7: 847-854.

Widom CS, DuMont K, Czaja SJ (2007). A prospective investigation of major depressive disorder and comorbidity in abused and neglected children grown up. Arch Gen Psychiatry 64: 49-56.
Xie P, Kranzler HR, Poling J, Stein MB, Anton RF, Brady K et al (2009). Interactive effect of stressful life events and the serotonin transporter 5-HTTLPR genotype on posttraumatic stress disorder diagnosis in 2 independent populations. Arch Gen Psychiatry 66: 1201-1209.

Yang BZ, Zhao H, Kranzler HR, Gelernter J (2005). Practical population group assignment with selected informative markers: characteristics and properties of Bayesian clustering via STRUCTURE. Genet Epidemiol 28: 302-312.

Zeger SL, Liang KY (1986). Longitudinal data analysis for discrete and continuous outcomes. Biometrics 42: 121-130.

Zhang H, Herman A, Kranzler HR, Anton RF, Zhao H, Zheng W et al (submitted for publication). Array-based profiling of DNA methylation: changes associated with alcohol dependence and influenced by childhood adversity.

Supplementary Information accompanies the paper on the Neuropsychopharmacology website (http://www.nature.com/npp) 